\title{
GENDER IN UNIVERSITIES AND PARTICIPATION IN GOVERNING BODIES
}

\author{
Ma Mar Durán Bellonch \\ Marina Tomàs Folch ${ }^{1}$ \\ Universitat Autònoma de Barcelona (UAB)
}

\begin{abstract}
:
It is a widely recognised phenomenon within Spanish universities that as the level of power and responsibility increases, so the number of women occupying elevated positions decreases. In view of the fact that university governance in Spain is based largely on a participatory system, the aim of our study was to observe how teaching staff participate in their governing bodies. Descriptive and exploratory in approach, our study examined participation in university governing bodies according to gender. The findings enabled us to identify trends rather than conclusions. These point to a style of participation among female teaching staff that is constructive, assertive, co-initiating and supportive. The results also highlighted variables other than gender that have a bearing on the type of participation.
\end{abstract}

Keywords: Participation; group; gender; university; management.

Corresponding author: $\mathrm{M}^{\mathrm{a}}$ Mar Durán Bellonch and Marina Tomàs Folch

E-mail: MariadelMar.duran@uab.cat; Marina.tomas@uab.cat

Submitted for publication 19/11/2012

Accepted for publication 21/12/2012

Educational Research eJournal ISSN 2254-0385

(C) Faculty of Education. University of Alicante

DOI: $10.5838 /$ erej.2013.21.03

\footnotetext{
${ }^{1}$ Members of the research group co-ordinated by Marina Tomàs (Agència de gestió d'ajuts universitaris $\mathrm{i}$
} recerca (AGAUR): File No. 2005RDG10003), also including: Lavié, J.M. and Guillamón, C. 


\section{Introduction}

It is a widely recognised phenomenon within Spanish universities that as the level of power and responsibility increases, so the number of women occupying elevated positions decreases (Tomàs, $\mathrm{M}$ et al. 2010). In view of the fact that university governance in Spain is based largely on a participatory system, the aim of our study was to observe how teaching staff participate in their governing bodies.

Our study, descriptive and exploratory in approach, was based on a theoretical model designed to identify categories of observation for types of participation during decision-making meetings of university governing bodies.

In addition, we sought the opinion of experts on reasons for different types of participation and for the low level of female representation at these meetings.

Our fundamental premise was that participation in meetings - and therefore university governance - must include the whole community on an equal basis. If female teaching staff are underrepresented and therefore unable to make their opinions heard, the decision-making process will suffer.

\section{Background}

Group participation in governing bodies is contextualised in the governing bodies of the university and has its theoretical benchmark in studies on participation according to gender.

In the Spanish university system, which provides the focus for this article, there are currently what are known as 'territorial' and 'central' bodies. Territorial bodies are those that are responsible for sectoral units of the university, such as faculties, departments, institutes and centres. The Permanent Council, for example, is a faculty body and the Department Council is a department body. The central governing bodies are the Board of Governors, the Social Council and the various committees (e.g. teaching staff, academic, economic and research committees) of each university. At Spanish universities academic staff may also have roles as professors or researchers. Furthermore, some professors also have management positions, since the heads, principals and rectors are elected by the university community.

The governing bodies take decisions that affect the university community, monitor plans of action and review procedures, etc. In short, work is done collectively and meetings are chaired by one person. The quality of participation in these bodies is important, since it greatly influences the degree to which the community is satisfied with what is being done and is largely fundamental to the representation of various opinions (Robbins, Stephen P. 1993).

But in Spain, as in other European countries such as the Czech Republic, Germany, Greece, France, the Flemish Community of Belgium, Austria, Switzerland, United Kingdom and Norway, there are more male university teachers than female, a fact substantiated by the Eurydice Report (2010). In concrete terms, in Spain only $36 \%$ of teachers at state universities are female (IFIIE e Instituto de la Mujer, 2009). Although some studies show that women have risen to higher positions with increased authority at universities in recent years, they are still underrepresented at the top of the hierarchy of power (Lips and Keener, 2007). Women are more inclined to teaching and research rather than management. In Spain only $14 \%$ of women are full professors (IFIIE $\mathrm{e}$ Instituto de la Mujer, 2009).

Morales, Luna and Esteban (2010) investigated whether election practices to governing bodies at Spanish universities affected the chances of women being appointed. In fact the authors came to the 
conclusion that when election to management posts applied a direct appointment approach, the presence of women was assured as a result of the recently introduced quota system. When the election system adopted the democratic approach, however, the imbalance was marked: in the majority of cases men were elected.

There are differences between men and women in communication styles, exercising of power and the acceptance of influence in decision-making meetings. In 1989, Smith-Lovin and Brody asserted that differences between the genders are in evidence when the structures of interruptions in meetings are analysed. Men had a tendency to interrupt much more frequently than women.

Studies into gender-based interaction do not always produce similar findings. Whereas Balwell and Berger (1996) affirmed the existence of gender differences in terms of the amount of output time in communicative relations, the frequency of gestures, the beginning of interaction and the fixation of gaze during it, previous studies such as those by Dindia (1987) and Mulac et al. (1987) point to differences only under certain circumstances. Dindia concludes that there are no differences in terms of interruption behaviour, although interruption frequency increases when the communicative relation is between different genders. In their study of dyads, Mulac et al. conclude that female-female dyads exhibited less one gazes/same talks and mutual avert/one talks than either male-male or female-male dyads. No differences were found between malemale and male-female dyads on any variable.

Hawkins and Power (1999) analysed the questions formulated in decision-making meetings and found that although there were no significant differences between the number of questions posed by men and women; however, there were differences as to the type of questions asked. Women tended to ask questions of an exploratory nature, inviting others to produce arguments and share information and opinions, giving an opportunity for others to exercise their influence.

Shackelford, Wood and Worchel (1996) found that women were more clearly motivated towards cooperation than their male colleagues.

In her later study, Carli (2001) concluded that men exercised less influence if the group was made up mainly of women. Men also displayed greater resistance to influence if it came from a woman.

LePine et al. (2002) asserts that in meetings attended only by men, the decisions taken are more aggressive than those taken in meetings attended by members of both sexes.

As far as we are aware, there have been no studies in the field of university management that look at differences in the style of participation in decisionmaking according to gender. On this basis our research team designed the study presented here. The starting point, however, centred on the results of a previous study that analysed decisionmaking meetings at universities.

On the basis of this study, we recognised a need to delve more deeply into the leadership style of female teaching staff at university and the way they accept influence being exercised by others. Put another way, our objective was to examine how women act with regard to power.

\section{Methodology}

A sample of eight meetings of various governing bodies was selected with a view to describing and understanding the interactions and dynamics within university governing bodies according to gender. The type of meetings selected included those involving a variety of 
committees and governing bodies in order that any observations made would not depend on meeting typology. The sampling approach was specifically selected for reasons of field access. Systematic observation by category was used as a research strategy in its traditional recording form. This was also for reasons of access to the scenario.

According to Bales' Interaction Process Analysis (Bales, 1970), a group is understood to be a system of individuals who interact, i.e. who perform a sequence of communicative actions and reactions of both a verbal and non-verbal nature. All the actions of the group may therefore be considered as interactions and can be analysed by means of systematic observation.

The starting point was a theoretical system of categories with an intermediate level of inference and the design of a very structured recording protocol pattern. Categories that had already been used in previous research were adapted for the study. Fabra (1992) modified the method designed by Horowitz, which in turn was based on the familiar Bales observation table (Bales, 1950). The author proposed a distinction between 'roles' and 'scripts', where the 'roles' are parts played by the members of a group during an interaction, and 'scripts' are the stage directions that accompany the text, as in a work for the theatre. Scripts are the non-verbal aspects that are indissolubly linked to the verbal aspects. They can also be thought of as describing the type of response to interpersonal power shown by those involved in this interaction process.

As previously mentioned, a checklist showing the absence/presence of behaviour was used to record the information, with each category referring to a specific form of conduct. The identity of the people at the meeting was not relevant; only their gender was considered of interest for the purpose of relating this variable with the absence or presence of categories in behaviour during the interaction.

Initially there were ten defined categories, although after a pilot test these were reduced to eight - four roles and four scripts-.Each interaction or communicative action was assigned to two categories: a role and a script. There was one exception, however: the so-called 'escape' script did not match any observable verbal conduct in that it specifically consisted of the noninvolvement of the person in group discussion at a verbal level.

The following is a summary of each of the categories defined:

Initiator role: a person who raises a new subject, a new question or who gives an opinion which is commented on by the rest of the group. As the name suggests, he/she takes the initiative as regards both the form and content of communication. Co-initiator role: a person who adds a relevant aspect to the comment by the initiator or introduces a variation on the subject proposed by the person initiating it, while asserting the validity of the ideas proposed by the latter and complementing them in some way.

Opposition role: a person who displays an intention to shift the framework of discussion, based on disagreement with the content or procedure or simply nonacceptance of the person leading the discussion at that point.

Supporter role: a person who agrees with the contributions of others without adding arguments of their own. Instead, any contributions they may make merely repeat what has been said by others.

The four scripts to be observed were:

Assertive script: a person who adopts a tone that is appropriate, purposeful and friendly. They know how to express what they want without hurting others, showing empathy but with firmness and self-confidence. 
Non-assertive script: a person who hesitates when making contributions, who talks in a low voice and often uses the conditional rather than the present tense ('I would say,' 'I would want' etc). $\mathrm{He} / \mathrm{she}$ withdraws quickly if anyone shows signs of opposition to their arguments.

Aggressive script: a person who speaks with an air of superiority or with contempt for others. He/she uses sarcasm and irony with regard to contributions made by other members of the group. $\mathrm{He} / \mathrm{she}$ interrupts, ignores and devalues.

Escape script: a person who, although present at the meeting, signals that he/she is elsewhere in thought. Such people may even leave the room in the middle of the discussion, answer a mobile phone, use the time to work on a document unrelated to the subject under discussion or talk to the person sitting next to them.

It was decided that a recording unit would be each oral contribution made by participants, plus the 'escape' script, which would not necessarily be accompanied by an oral contribution. It was also decided that the duration of the recording would be the same as the duration of the meeting of the governing body being studied. Observation, recording and encoding would take place simultaneously in order to facilitate the work of the researcher in the field.

It was acknowledged that the categories defined are not exclusive to people involved in a university governing body, but can also be used to analyse various group interaction processes in which the focus is on studying participation-related phenomena and the exercise of interpersonal power.

One or two categories would be recorded for each contribution made by a person in the group (recording unit): a role and/or a script, distinguishing the gender of the contributor with a predetermined symbol. All interactions would be recorded without identifying the people involved other than noting their gender. This information was not relevant to the established objectives and its omission increased the effectiveness of the observer.

Once the theoretical categories and details of the observation process had been defined, the field studies began.

\section{The observations}

The research group carried out a total of eight observations of the different governing bodies of two universities - U1 and U2-.

The governing bodies observed were: a research committee, department councils, (representing different areas of knowledge), a permanent council and an academic committee.

The number of people taking part in all meetings observed totalled 199, of which 97 were women and 102 were men.

Observations were made in terms of contributions rather than individuals, as a result of which the number of contributions catalogued was 796 .

The size of the committees or governing bodies was a variable which, although not a research objective, appeared to have a determining influence on participation.

As regards agenda and the way in which decisions are taken, it was noted that voting is increasingly less common as a decision-making system. In general, consensus is the norm and there is no counting of votes.

'Decisions were taken by consensus or unanimity.' (Description 1 Observer)

Any information or documentation required for active participation in the meeting was usually made available to participants via Internet, with paper copies provided at the meeting itself.

'A beamer and written documents were required to present the points on the agenda. Everyone had the information necessary to play an active part in the meeting.' (Description 1 Observer)

'Following the agenda point by point, 
those present at the meeting participated once each item had been introduced by the co-ordinator.' (Description 2 Observer) 'Although certain points on the agenda offered little room for debate - being merely informative - others were highly participatory and gave rise to lively debate and an exchange of ideas and opinions. On occasions, discussion had to be curtailed to allow the meeting to continue.' (Description 7 Observer)

'After approximately two hours the director amicably brought the meeting to a close, having dealt with all the points on the agenda.' (Description 3 Observer)

The duration of meetings varied substantially, but in general they were under two hours in length.

'In general the meetings were short (as compared with other meetings), lasting approximately an hour and a half.' (Description 6 Observer)

'The session ended after approximately 3 hours 45 minutes.' (Description 7 Observer)

'The meeting ended after 3 hours.' (Description 8 Observer)

\section{Results in terms of 'scripts' exercised}

Table 1 shows the distribution of contributions catalogued as 'scripts' by the observer according to gender for each meeting observed. 1321 interactions were catalogued as scripts. Of these, 796 were classed as interaction scripts, meaning that each script was assigned a role, and 525 were classed as 'escape' scripts.

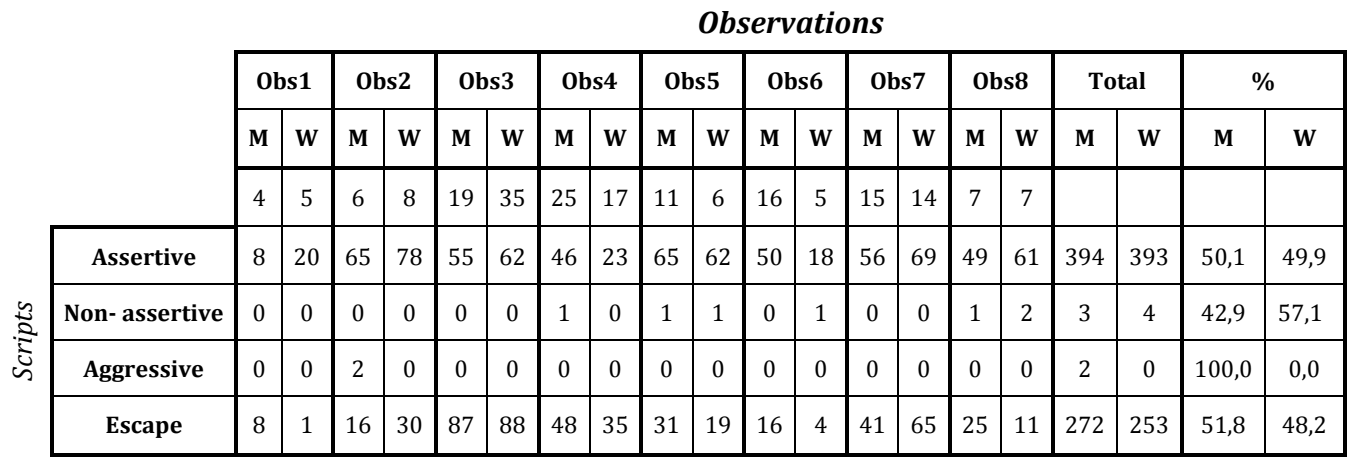

Table 1. Distribution of scripts for each observation made.

The meetings observed consisted of people who either represent the academic sector at its various hierarchical levels or are ex officio members owing to their management responsibilities. Members of these committees/meetings are present on account of their position, so that by participating they exercise a powerful influence on the decision-making process. In terms of the most frequent type of behaviour, almost three quarters of interactions observed were presented in a tone that was reasonable, purposeful and friendly, i.e. what we have designated an 'assertive script'. It should be remembered that these observations include those interventions made by the person coordinating the meeting and others assisting with coordination.

Of particular interest after analysis of all observations was the low number of non-assertive contributions. This may indicate that those making such contribution do so when they are very sure of what they are going to say or simply say nothing.

There were also a very low number of aggressive contributions, which may be consistent with an atmosphere of friendliness prevailing at these meetings. A little less than half of all observations catalogued as scripts were of the 
'escape' type, which does not seem to be an indicator of participatory health if it is interpreted as conduct taking place showing absence in its various facets (mind elsewhere, occupied with something else, answering mobile phone, etc.).
In terms of the number of contributions classified as scripts, it was noted that these were made by both male and female participants equally, with the exception of 'aggressive scripts', which would appear to be a male preserve (see Figure 1).

Figure 1. Comparison of scripts according to gender for all observations.

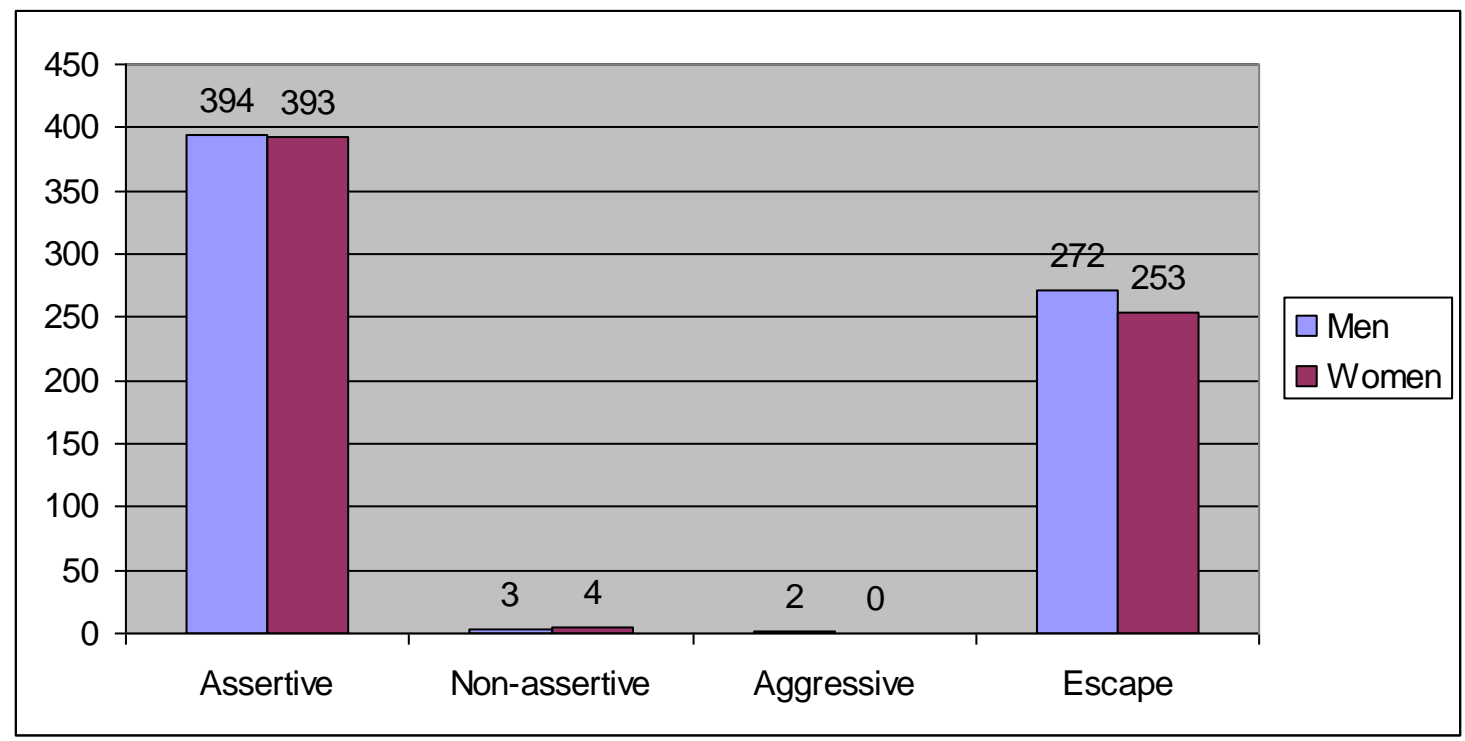

\section{Results in terms of roles played}

Table 2 shows the distribution of contributions catalogued as roles by the observer according to gender for each meeting observed. The number of interactions catalogued as roles was 796.

The role played by each person in a meeting was observed based on the types set out above. The coordinator was usually the person whose contribution could be aligned with the initiator role; this role was played more frequently by men $(57.8 \%)$ than by women $(42.2 \%)$. The reverse is true of the co-initiator role, which is played more often by women $(52.3 \%)$ than by men $(47.7 \%)$. On the other hand, women show more assertive behaviour in meetings that are conducted by another woman. This forces us to question whether the fact of a meeting being conducted by a man may in some way inhibit a woman's capacity to behave assertively.

In any event, it is important to stress that the combined contributions with 'initiator' and 'co-initiator roles' account for two thirds of the total of all contributions observed.

Particularly striking is the low number of 'opposition roles' - as compared with 'support' or 'following roles' - in subjects initiated by the meeting coordinator.

A quarter of all roles were of a supportive nature and these were played more by women $(57.7 \%)$ than by men $(42.3 \%)$.

With respect to roles (Figure 2) a trend can be identified in which the male is more commonly an initiator and more frequently plays the opposition role. However, the roles of co-initiator and supporter are more common among females. 


\section{Observations}

\begin{tabular}{|c|c|c|c|c|c|c|c|c|c|c|c|c|c|c|c|c|c|c|c|c|}
\hline & \multicolumn{2}{|c|}{ Obs1 } & \multicolumn{2}{|c|}{ Obs2 } & \multicolumn{2}{|c|}{ Obs3 } & \multicolumn{2}{|c|}{ Obs4 } & \multicolumn{2}{|c|}{ Obs5 } & \multicolumn{2}{|c|}{ Obs6 } & \multicolumn{2}{|c|}{ Obs7 } & \multicolumn{2}{|c|}{ Obs8 } & \multicolumn{2}{|c|}{ Total } & \multicolumn{2}{|c|}{$\%$} \\
\hline & $\mathbf{M}$ & $\mathbf{w}$ & M & $\mathbf{W}$ & M & $\mathbf{w}$ & M & $\mathbf{W}$ & M & $\mathbf{w}$ & M & $\mathbf{w}$ & M & $\mathbf{w}$ & M & $\mathbf{w}$ & M & w & M & $\mathbf{w}$ \\
\hline & 4 & 5 & 6 & 8 & 19 & 35 & 25 & 17 & 11 & 6 & 16 & 5 & 15 & 14 & 7 & 7 & & & & \\
\hline Initiator & 1 & 5 & 23 & 15 & 20 & 22 & 17 & 8 & 20 & 10 & 18 & 3 & 21 & 14 & 25 & 29 & 145 & 106 & 57,8 & 42,2 \\
\hline Co-initiator & 4 & 11 & 18 & 27 & 16 & 22 & 15 & 6 & 25 & 36 & 23 & 11 & 23 & 24 & 19 & 20 & 143 & 157 & 47,7 & 52,3 \\
\hline Opposition & 1 & 1 & 4 & 1 & 2 & 0 & 2 & 0 & 4 & 2 & 0 & 0 & 1 & 0 & 3 & 2 & 17 & 6 & 73,9 & 26,1 \\
\hline Supporter & 2 & 3 & 22 & 35 & 17 & 18 & 13 & 9 & 18 & 16 & 9 & 4 & 10 & 31 & 3 & 11 & 94 & 128 & 42,3 & 57,7 \\
\hline
\end{tabular}

Table 2. Distribution of roles for each observation made.

Figure 2. Comparison of roles according to gender in all observations.

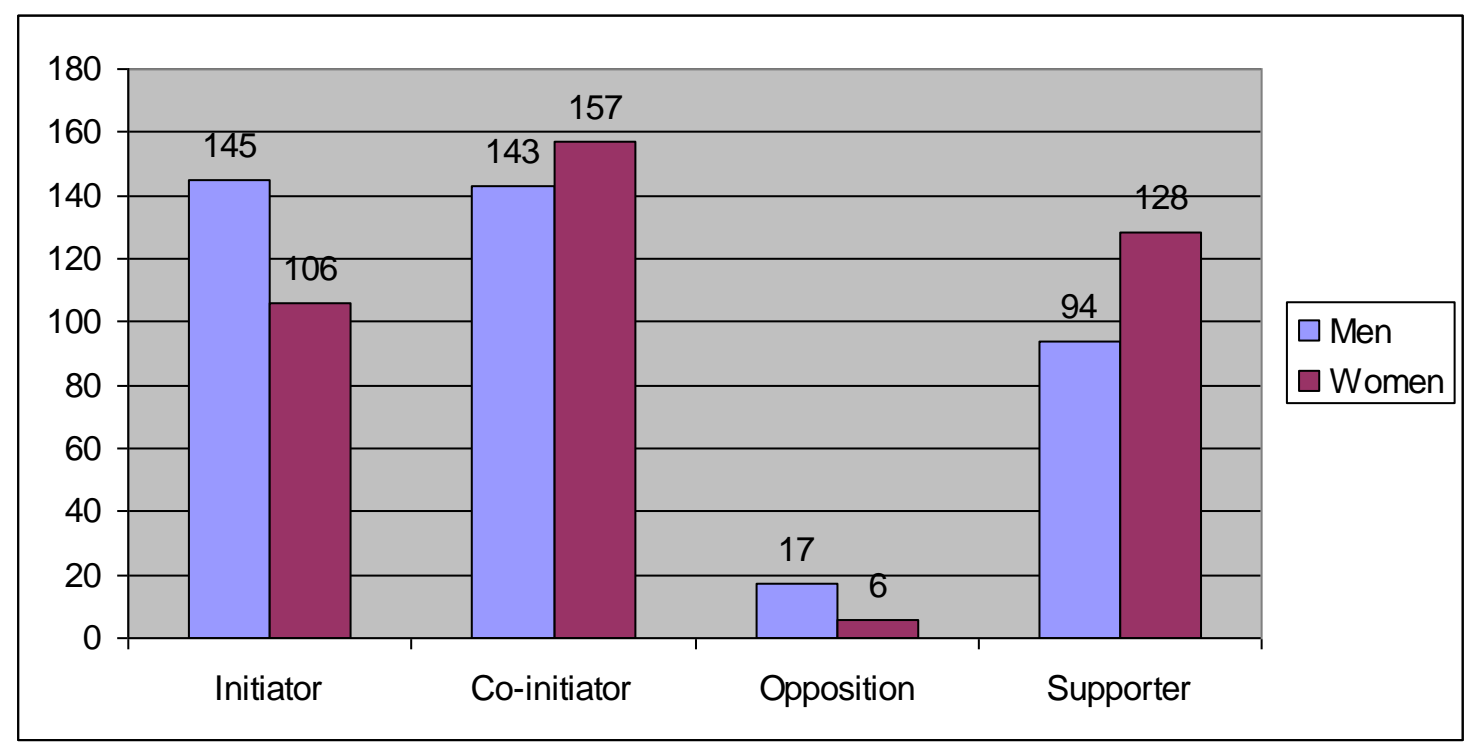

\section{Conclusions}

The type of observations made and the data collected permit identification of trends rather than conclusions.

Contributions by participants were almost always constructive, positive and aligned with the person coordinating the meeting. There were very few contributions of the 'opposition' type; if observed at all, these were voiced by men. Possible explanations for this are the fact that opposition is not considered worthwhile, or that proposals by the heads of the governing bodies are so apposite and well prepared that they leave little room for criticism.
Although gender appears to have a clear influence on the style of participation, it is perhaps not the only aspect to influence perceptible behaviour differences in decision-making processes.

In addition to gender, other factors were identified which affect the quality of participation in governing bodies, such as the age of those participating and the size of the group. Older people tended to participate more than young people and the greater the number of participants in a meeting, the more difficult it was for all to make a contribution.. These factors should be taken into account for future study. The coordinator's style of leadership 
was another factor that appeared to condition the type of contribution. Of the eight meetings observed, only three were coordinated by women, which perhaps explains why the role of initiator was played more often by men than by women. However, the observations suggest there was greater participation by women in the role of co-initiators and supporters in meetings coordinated by women. In fact, generally speaking, when the meeting was chaired by a woman, there was greater participation and discussion was more evenly distributed between men and women (for all roles and all scripts). It could therefore be asserted that the quality of decision-making in meetings chaired by women would improve, assuming one accepts the premise that quality of decision-making improves as a result of better participation distribution.

In addition to the gender of the person coordinating the meeting, it appears that the style of coordination and/or type of leadership of the meeting coordinator has a decisive influence on the quality of participation and decision-making. Broadly speaking, and taking due caution into account, it is possible to distinguish a 'female style' of participation, which matches results obtained by Hawkins and Power (1999). This style is characterised by the use of direct and concise contributions, a search for dialogue and consensus, articulation of more pragmatic approaches, as well as concern for aspects related to the process and not just with the contents of decision-making. This approach has a positive effect on participation.

The 'male style' of participation in university government bodies, on the other hand, also has its strengths. One of these is the male ability to assertively play an opposition role.

At this point we must ask ourselves to what extent there is reason and purpose behind Krüger's rationale (2007) that discussion of gender differences should cease and that we may be better served by recognising the benefits to be gained by "turning differences between the sexes to our advantage in mixed management teams." (Krüger, 2008).

In our opinion one important detail should not be neglected: if we are to harness all available forces, it is imperative that all obstacles preventing women from accessing management roles be removed; unfortunately in many countries this is not yet the case (Morrison, 1992; Blackmore and Sachs, 2000; Young and McLeod, 2001; McClay and Brown, 2001; Björk, 2000; Celikten, 2005).

Once there is equal opportunity for access to leadership positions, it will still be necessary to ensure that the respective strengths of male and female styles of management are considered on equal terms. We believe there is a need to undertake pedagogic measures to target this objective and researchers are invited to explore this subject in greater depth.

Finally, it should be noted that this research represents an initial analysis of the study into participation according to gender in university governing bodies. The aim has not been to generalise results, since the study is exploratory and descriptive in nature. Moreover, one of the objectives established by the research team for the near future is to improve tools of observation. 


\section{References}

Bales, R. F. (1950). Interaction process analysis: Method for study of small groups. Cambridge: Addison-Wesley. [Back to text]

Bales, R. F. (1970). Personality and interpersonal behaviour. New York: Holt, Rinehart and Winston. [Back to text]

Balwell, J. W. \& Berger, J. (1996). Gender, status and behaviour in task situations. Social Psychology Quarterly, 59(3), 273-283. [Abstract] [Back to text]

Björk, L.G. (2000). Introduction: women in the superintendencyadvances in research and theory. Educational Administration Quarterly, 36, 5-17. [Full text] [Back to text]

Blackmore, J. \& Sachs, J. (2000). Paradoxes of leadership and management in higher education in times of change: some Australian reflections. International Journal of Leadership in Education, 3(1), 116. [Abstract] [Back to text]

Carli, L. L. (2001). Gender and social influence. Journal of Social Issues, 57(4), 725-741. [Full text] [Back to text]

Celikten, M. (2005). A perspective on women principals in Turkey. International Journal of Leadership in Education, 8(3), 207-221. [Abstract] [Back to text]

Dindia, K. (1987). The Effects of Sex of Subject and Sex of Partner on Interruptions. Human Communication Research. 13(3), 345-371. doi:10.1111/j.1468 2958..1987.tb00109.x [Abstract] [Back to text]

Education, Audiovisual and Culture Executive Agency .(2010). Gender Differences in Educational Outcomes: Study on the Measures Taken and the Current Situation in Europe. European Commission, Eurydice Fabra, M.Ll. [Full text] [Back to text]

Hawkins, K. \& Power, C. B. (1999). Gender differences in questions asked during small decisionmaking group discussions. Small Group Research, 30(2), 235256. [Full text] [Back to text]

IFIIE \& Instituto de la Mujer, (2009). Las mujeres en el sistema educativo II. Colección de estudios Mujeres en la Educación, 12. Madrid: IFIIE \& Instituto de la Mujer. [Full text] [Back to text]

Krüger, M. (2008). School leadership, sex and gender: welcome to the difference. International Journal of Leadership in Education, 11(2), 155-168. [Abstract] [Back to text]

LePine, J. A., Hollenbeck, J. R., Ilgen, D. R., Colquitt, J. A. \& Ellis, A. (2002). Gender composition, situational strength, and team decision-making accuracy: a criterion decomposition approach. Organizational Behavior and Human Decision Processes, 88(1), 445-475. [Abstract] [Back to text]

McClay, M. \& Brown, M. (2001). Preparation and training for school leadership: case studies of nine women head teachers in the secondary independent 
sector. School Leadership and Management, 21, 101-115. [Abstract] [Back to text]

Morales, M. J., Luna, M. J. \& Esteban, A. I. (2010). Diagnóstico de paridad en la universidad: análisis a través de indicadores. Revista de Universidad $y$ Sociedad del Conocimiento, 7(2), 1-14. [Full text]

[Back to text]

Morrison, A. M., White, R. P. \& Van Nelson, E. (1992). Breaking the glass ceiling. Cambridge: Addison-Wesley. [Back to text]

Mulac, A., Studley, L., Wiedmann, J. \& Bradac, J. (1987). Male/Female Gaze in Same-Sex and Mixed-Sex Dyads Gender-Linked Differences and Mutual Influence. Human Communication Research, 13(3), 323 343.doi:10.1111/j.14682958.1987.tb00108.x [Abstract] [Back to text]

Robbins, Stephen P. (1993). Comportamiento organizacional
( $6^{\mathrm{a}}$ edición). México: Prentice Hall. [Full text] [Back to text]

Smith-Lovin, L. \& Brody, C. (1989). Interruptions in group discussions: the effects of gender and group composition. American Sociological Review, 54(3), 424-435. [Abstract] [Back to text]

Tomàs, M., Duran, M. M., \& Lavié, J. M. (2010). Women in Academic Administration at the University. Educational Management Administration and Leadership, 38(4), 487-498. [Full text] [Back to text]

Young, M. D. \& McLeod, S. (2001). Flukes, opportunities and planned interventions: factors affecting women's decisions to become school administrators. Educational Administration Quarterly, 37(4), 462-502. [Full text] [Back to text] 